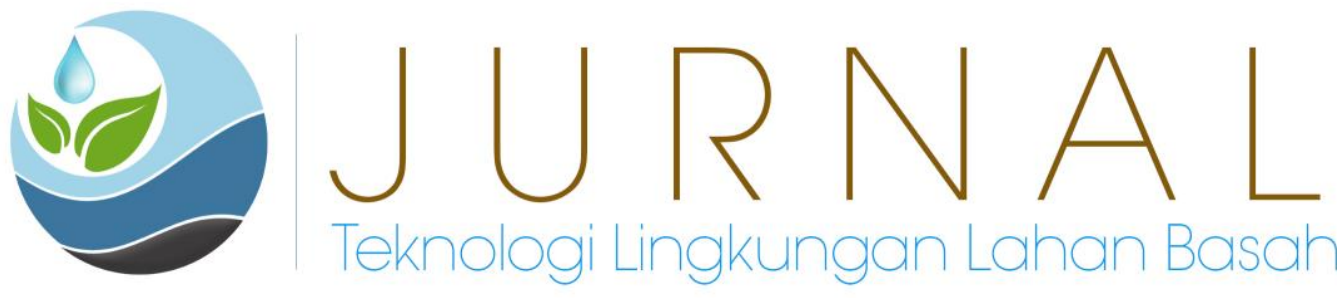

\title{
STRATEGI PENGELOLAAN SAMPAH MELALUI ANALISIS TIMBULAN DAN KARAKTERISTIK SAMPAH DI UNIVERSITAS NAHDLATUL ULAMA KALIMANTAN BARAT
}

\author{
Ricka Aprillia $^{1}$ dan Ika Muthya Anggraini' ${ }^{2}$ \\ ${ }^{1}$ Jurusan Teknik Pertambangan Universitas Tanjungpura \\ ${ }^{2}$ Teknik Lingkungan Universitas Nahdlatul Ulama Kalimantan Barat \\ Email: ${ }^{1}$ rickaaprillia1990@gmail.com dan 2ikamuthya@yahoo.com
}

\begin{abstract}
College or university is one place that has high waste production potential. As a tertiary institution, UNU West Kalimantan continues to experience the development of building quantity and the development of human resources, namely an increase in the number of students, educators and education staff. These developments led to an increase in activities that impacted on the amount of waste generated from each activity. Waste that is not managed properly will have a bad impact on the environment because it will disrupt the aesthetics, cause odors and interfere with the teaching process. The purpose of this study was to determine the amount of generation, composition and characteristics of waste produced and formulate a waste management system strategy such as operational technical, storage, collection and processing of waste in the UNU West Kalimantan. This research was conducted in January to December 2019 and located in the UNU West Kalimantan. The object of this research is the waste generated at UNU West Kalimantan. The research procedures carried out consisted of four stages, namely the preparation phase, the stage of data collection, the stage of data analysis and planning, and the final stage, namely the output of research results. Measurement and sampling methods use SNI 19-3964-1994, and data analysis using formulas and existing rules in accordance with the planning approach. From the results of the study note that the generation of waste generated from the four faculties and canteens in West Kalimantan UNU amounted to $476.42 \mathrm{~L} /$ day or $41.42 \mathrm{~kg} /$ day. The composition of UNU Kalbar's waste consists of organic waste at $3.37 \mathrm{~kg} /$ day, paper at 11.55 $\mathrm{kg} /$ day, wood at $1.58 \mathrm{~kg} /$ day, plastic at $24.15 \mathrm{~kg} /$ day, and B3 waste at $0,37 \mathrm{~kg} /$ day. From the composition of the waste, the most common type of waste is plastic waste. From the generation and composition data, it is planned that the amount of storage needs with a volume of $50 \mathrm{~L}$ is 10 pieces that will be placed in each faculty and canteen. Waste that has been produced will then be collected by officers and disposed of at the Temporary Disposal Site (TPS). The location of the TPS is planned to be located in the area behind the campus with consideration so as not to disturb the aesthetics and avoid odor generation. The garbage transportation route starts from the front area of the building to the back of the campus. Garbage collection services use one motorized garbage collection wagon with a capacity of $2.5 \mathrm{~m}^{3}$.
\end{abstract}

Keywords: waste management strategy; West Kalimantan UNU; operational techniques; generation; garbage characteristics 


\begin{abstract}
Abstrak
Perguruan tinggi atau universitas merupakan salah satu tempat yang memiliki potensi produksi sampah yang tinggi. Sebagai suatu perguruan tinggi, UNU Kalbar terus mengalami perkembangan kuantitas bangunan maupun perkembangan sumber daya manusia yaitu peningkatan jumlah mahasiswa, tenaga pendidik dan tenaga kependidikan. Perkembangan tersebut menyebabkan peningkatan aktivitas yang berdampak pada jumlah sampah yang dihasilkan dari setiap kegiatan. Sampah yang tidak dikelola dengan baik akan berdampak buruk bagi lingkungan karena akan mengganggu estetika, menimbulkan bau dan mengganggu proses pengajaran. Tujuan penelitian ini adalah mengetahui jumlah timbulan, komposisi dan karakteristik sampah yang dihasilkan serta menyusun strategi sistem pengelolaan sampah seperti teknis operasional, pewadahan, pengumpulan dan pengolahan sampah di kawasan UNU Kalbar. Penelitian ini dilaksanakan pada bulan Januari hingga Desember 2019 dan berlokasi di kawasan UNU Kalbar. Objek dalam penelitian ini adalah sampah yang dihasilkan di UNU Kalbar. Adapun prosedur penelitian yang dilakukan terdiri dari empat tahap yaitu tahap persiapan, tahap pengumpulan data, tahap analisis data dan perencanaan, dan tahap akhir yaitu output hasil penelitian. Metode pengukuran dan sampling menggunakan SNI 19-3964-1994, dan analisis data dengan menggunakan rumus dan aturan-aturan yang ada sesuai dengan pendekatan perencanaan. Dari hasil penelitian diketahui bahwa timbulan sampah yang dihasilkan dari empat fakultas dan kantin yang berada di UNU Kalbar sebesar 476,42 L/hari atau 41,42 kg/hari. Komposisi sampah UNU Kalbar yaitu terdiri dari sampah organik sebesar 3,37 kg/hari, kertas sebesar 11,55 kg/hari, kayu sebesar 1,58 kg/hari, plastik sebesar 24,15 kg/hari, dan limbah B3 sebesar 0,37 kg/hari. Dari komposisi sampah tersebut jenis sampah yang paling banyak ditemukan yaitu sampah plastik. Dari data timbulan dan komposisi tersebut direncanakan jumlah kebutuhan pewadahan dengan volume $50 \mathrm{~L}$ yaitu sebanyak 10 buah yang akan ditempatkan pada tiap fakultas dan kantin. Sampah yang telah dihasilkan kemudian akan dikumpulkan oleh petugas dan dibuang ke Tempat Pembuangan Sementara (TPS). Lokasi TPS ini direncanakan terletak di area belakang kampus dengan pertimbangan agar tidak mengganggu estetika dan menghindari timbulan bau. Rute pengangkutan sampah dimulai dari area depan bangunan hingga ke area belakang kampus. Pelayanan pengumpulan sampah menggunakan satu gerobak motor pengumpul sampah dengan kapasitas $2,5 \mathrm{~m}^{3}$.
\end{abstract}

Kata kunci : strategi pengelolaan sampah; UNU Kalbar; teknik operasional; timbulan; karakteristik sampah

\title{
PENDAHULUAN
}

Universitas Nahdlatul Ulama Kalimantan Barat (UNU Kalbar) didirikan pada tahun 2014 dan mulai beroperasi pada tahun 2015. Sebagai suatu perguruan tinggi, UNU Kalbar merupakan suatu institusi pendidikan tinggi yang berlokasi di dalam suatu kawasan yang terus menerus mengalami perkembangan. Gedung UNU Kalbar terletak di lokasi strategis yaitu di Jalan Parit Derabak Kabupaten Kubu Raya. Di awal pendirian sampai saat ini UNU Kalbar telah membuka empat Fakultas yaitu Fakultas Keguruan dan Ilmu Pendidikan, Fakultas Ekonomi, Fakultas Pertanian dan Fakultas Teknik yang memiliki sepuluh progam studi. Selain itu, juga terdapat aula universitas, UPT perpustakaan, UPT Bahasa, UPT Bimbingan Konseling.

UNU Kalbar terus mengalami perkembangan kuantitas bangunan maupun perkembangan sumber daya manusia yaitu peningkatan jumlah mahasiswa, tenaga pendidik dan tenaga kependidikan. UNU Kalbar memiliki mahasiswa regular, dosen tetap dan dosen tidak tetap serta pegawai administrasi pada tingkat universitas maupun fakultas yang terus meningkat 
setiap tahunnya. Perkembangan tersebut menyebabkan peningkatan aktifitas yang berdampak pada jumlah sampah yang dihasilkan dari setiap kegiatan. Sampah yang dihasilkan dari berbagai kegiatan di tiap fakultas akan menghasilkan sampah yang beragam (Purnaini, 2011)

Perguruan tinggi atau universitas merupakan salah satu tempat yang memiliki potensi produksi sampah yang tinggi. UNU Kalbar sebagai salah satu pusat kegiatan pendidikan yang menghasilkan sampah seperti bagunan pendidikan lainnya. Sampah yang biasa dihasilkan berasal dari kegiatan belajar mengajar, sampah organik, dan sampah anorganik. Sampah organik berasal dari sisa-sisa makanan atau jajanan mahasiswa dari kantin atau warung serta sampah rumput dan tanaman dari taman yang berada di lingkungan sampah (Fadilah, 2011). Sampah tersebut belum dikelola dengan baik dikarenakan kurangnya fasilitas sarana dan prasarana untuk pengelolaan sampah seperti, kuantitas dan kualitas pewadahan yang tidak layak, pengumpulan tidak sesuai jadwal sehingga menyebabkan terbentuknya lindi pada wadah sampah yang masih tercampur. Penanganan sampah di tiap fakultas juga masih menggunakan cara lama yaitu sampah dikumpulkan ke suatu tempat pengumpulan (TPS) terdekat yang kemudian ada yang dibakar dan sebagian berakhir di tempat pemrosesan akhir (TPA). Sampah yang tidak dikelola dengan baik akan berdampak buruk bagi lingkungan karena akan mengganggu estetika, menimbulkan bau dan mengganggu proses pengajaran. Dengan produksi sampah yang banyak dan beragam, maka perlu dilakukan studi identifikasi komposisi dan karakteristik sampah serta jumlah timbulan sampah yang dihasilkan di bangunan pendidikan tinggi UNU Kalbar. Tujuan penelitian ini adalah mengetahui jumlah timbulan, komposisi dan karakteristik sampah yang dihasilkan serta menyusun strategi sistem pengelolaannya seperti teknis operasional, pewadahan, pengumpulan dan pengolahan sampah di kawasan UNU Kalbar.

\section{METODE PENELITIAN}

Lokasi penelitian terletak di kampus UNU KALBAR yang terletak di Jalan Parit Deraba, Kecamatan Sungai Raya Kabupaten Kubu Raya. Kawasan UNU KALBAR memiliki luas wilayah $\pm 2,2 \mathrm{Ha}$. Secara geografis, UNU Kalbar terletak pada titik $0^{\circ} 066^{\prime} 38,1^{\prime \prime} \mathrm{LS}$ dan $109^{\circ}$ 22' 24,0" BT. Peta letak kampus UNU KALBAR dapat dilihat pada gambar 1.

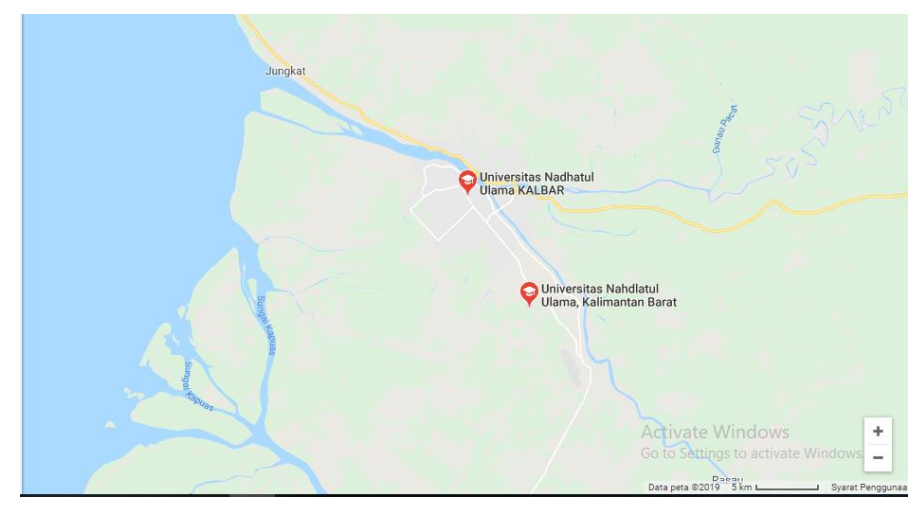

Gambar 1. Peta lokasi kampus UNU KALBAR

Data yang digunakan dalam penelitian ini meliputi data primer dan data sekunder. Data primer berupa data timbulan/volume, berat, komposisi, dan karakteristik sampah merupakan data yang didapat dari hasil sampling. Data ini digunakan untuk merencanakan pengelolaan sampah meliputi jumlah wadah, jumlah sarana pengumpul dan Tempat Pembuangan 
Sementara (TPS). Data primer lain yaitu data hasil pengamatan di lokasi penelitian yang meliputi kondisi eksisting pewadahan dan TPS serta teknik operasional pengelolaan sampah di UNU KALBAR. Data ini digunakan untuk mengetahui kondisi yang ada sekarang. Kemudian data sekunder yang digunakan berupa profil Universitas Nahdlatul Ulama Kalbar, master plan dan data eksisting pengelolaan sampah dan kelengkapannya diambil dari Biro Administrasi dan Perencanaan dan Sistem Informasi Rektorat, data jumlah mahasiswa yang diambil dari bagian akademik, dan data jumlah tenaga pendidik dan tenaga kependidikan.

Peralatan yang digunakan untuk pengambilan sampel sampah yaitu timbangan, sarung tangan, masker, plastik sampah, kotak $40 \mathrm{~L}$, penggaris, dan terpal. Pengambilan sampel sampah untuk tiap sumber sampah yang ada di kawasan UNU Kalbar dilakukan setiap hari pada pukul 08.00 pagi. Pengambilan sampah dilakukan selama 5 hari secara terus menerus dengan justifikasi bahwa kegiatan belajar dan aktifitas mahasiswa yang paling padat terjadi pada hari Senin hingga Jumat. Data-data yang sudah dikumpulkan kemudian dianalisis dengan menggunakan pendekatan dalam perencanaan pengelolaan sampah. Hasil analisis yang akan dijadikan pertimbangan dalam perencanaan yaitu jumlah civitas akademika, timbulan sampah, berat jenis sampah dan komposisi sampah.

\section{HASIL DAN PEMBAHASAN \\ Kondisi Eksisting UNU KALBAR}

Hingga saat ini, UNU KALBAR memiliki empat fakultas dan sepuluh program studi dengan jenjang pendidikan Strata Satu (S-1). Pada awal berdiri, gedung UNU KALBAR berlokasi di pusat Kota Pontianak dengan bangunan yang cukup kecil dengan ketersediaan lahan seadanya. Namun melalui perencanaan dan pembangunan yang telah dilakukan secara bertahap, UNU KALBAR sudah memiliki gedung yang memadai dengan luas lahan sebesar 2,2 Ha. Gedung baru tersebut berlokasi di jalan parit deraba, Kecamatan Sungai Raya Kabupaten Kubu Raya yang akan dilakukan perencanaan fasilitas persampahan pada penelitian ini. Saat ini, UNU KALBAR sudah memiliki \pm 304 mahasiswa, \pm 45 tenaga pendidik dan tenaga kependidikan dan akan cenderung meningkat setiap tahunnya. Peningkatan jumlah warga UNU KALBAR ini akan berdampak pada peningkatan jumlah sampah secara signifikan. Sampah yang dihasilkan UNU KALBAR secara keseluruhan belum dikelola secara baik. Hal ini dapat dilihat dari kapasitas pewadahan sampah yang tidak memadai sehingga sampah tersebut seringkali berserakan diluar kapasitas tempat sampah. Pewadahan seperti ini tidak sesuai kriteria dikarenakan akan menimbulkan bau tidak sedap dan juga tidak baik secara estetika di lingkungan kampus. Sampah dari masing-masing fakultas tersebut dikumpulkan setiap pagi pada pukul 07.00 oleh petugas sampah, kemudian dilakukan pengangkutan ke TPS terdekat. Selanjutnya pengelolaan sampah di TPS dilakukan oleh Dinas Pekerjaan Umum Bidang Cipta Karya Kabupaten Kubu Raya.

\section{Analisis Timbulan Sampah}

Timbulan sampah yang dianalisis merupakan hasil pengumpulan secara keseluruhan dari setiap fakultas selama lima hari. Analisis hasil pengukuran sampel timbulan sampah yang dihasilkan dari tiap fakultas berupa volume sampah disajikan dalam tabel 1 dan tabel 2 berikut : 
Tabel 1. Hasil Pengukuran Volume Sampah di Setiap Fakultas dan Kantin di UNU Kalbar

\begin{tabular}{|c|l|r|r|r|r|r|c|}
\hline \multirow{2}{*}{ No } & Sumber Sampah & 9 Juli & $\mathbf{1 0 ~ J u l i}$ & $\mathbf{1 1}$ Juli & 12 Juli & 13 Juli & $\begin{array}{c}\text { Rata-rata } \\
\text { Volume } \\
\text { (Liter) } \\
\text { Sampah/Hari }\end{array}$ \\
\cline { 3 - 8 } & & & & & 85.5 & 93.1 \\
\hline 1 & Fakultas Ekonomi & 124.8 & 92.6 & 68 & 95.6 & 84.5 & 144.88 \\
\hline 2 & FKIP & 131.2 & 165.2 & 133.9 & 159.3 & 134.8 & 87.63 \\
\hline 3 & Fakultas Pertanian & 67.2 & 106.8 & 85.6 & 95.75 & 82.8 & 123.05 \\
\hline 4 & Fakultas Teknik & 112 & 144.3 & 117.45 & 112.8 & 128.7 & 27.76 \\
\hline 5 & Kantin & 26.5 & 24 & 29.4 & 27.4 & 31.5 & $\mathbf{4 7 6 , 4 2}$ \\
\hline \multicolumn{7}{|c|}{ Total } \\
\hline
\end{tabular}

Sumber: Survey, 2019

Berdasarkan hasil pengukuran volume timbulan sampah di setiap fakultas dan kantin di UNU Kalbar bahwa rata-rata volume timbulan sampah di UNU Kalbar sebanyak 476,42 liter/hari. Timbulan sampah tersebut bersumber pada 4 fakultas dan 1 kantin. Selain itu, penelitian ini juga melakukan pengukuran berat sampah di setiap fakultas dan kantin di UNU Kalbar. Hasil pengukuran berat sampah tersebut dapat dilihat pada tabel 2 .

Tabel 2. Hasil Pengukuran Berat Sampah di Setiap Fakultas dan Kantin di UNU Kalbar

\begin{tabular}{|c|c|c|c|c|c|c|c|}
\hline \multirow[b]{2}{*}{ No } & \multirow[b]{2}{*}{ Sumber Sampah } & \multicolumn{5}{|c|}{ Berat (Kg) } & \multirow{2}{*}{$\begin{array}{c}\text { Rata-rata } \\
\text { Berat (Kg) } \\
\text { Sampah/Hari }\end{array}$} \\
\hline & & 9 Juli & 10 Juli & 11 Juli & 12 Juli & 13 Juli & \\
\hline 1 & Fakultas Ekonomi & 8.9 & 8.2 & 5.7 & 7.8 & 6.5 & 7.42 \\
\hline 2 & FKIP & 11.7 & 12.3 & 10.3 & 11.8 & 10.7 & 11.36 \\
\hline 3 & Fakultas Pertanian & 9.1 & 8.9 & 6.3 & 7.5 & 6.7 & 7.7 \\
\hline 4 & Fakultas Teknik & 12.3 & 11.1 & 8.7 & 10.2 & 11.7 & 10.8 \\
\hline 5 & Kantin & 3.8 & 3.9 & 4.2 & 3.8 & 4.5 & 4.04 \\
\hline \multicolumn{7}{|c|}{ Total } & 41.42 \\
\hline
\end{tabular}

Sumber: Survey, 2019

Berdasarkan hasil pengukuran berat timbulan sampah di setiap fakultas dan kantin di UNU Kalbar bahwa rata-rata berat timbulan sampah di UNU Kalbar sebanyak 41,42 kg/hari. Timbulan sampah tersebut bersumber pada 4 fakultas dan 1 kantin.

\section{Komposisi Sampah}

Pengukuran komposisi timbulan sampah pada penelitian ini mengacu pada SNI 19-3964-1994 tentang metode pengambilan dan pengukuran contoh timbulan sampah perkotaan. Dalam pengukuran ini, komposisi sampah dikategorikan menjadi 5 kategori yaitu sampah organik, sampah kertas, sampah kayu, sampah plastik dan limbah B3. Komposisi rata-rata timbulan sampah per hari pada setiap fakultas dan kantin di UNU Kalbar secara terperinci dapat dilihat pada Tabel 3. 
Tabel 3. Hasil Pengukuran Komposisi Sampah Rata- Rata per Hari di Setiap Fakultas dan Kantin di UNU Kalbar

\begin{tabular}{|c|l|r|r|r|r|r|}
\hline \multirow{2}{*}{ No } & \multirow{2}{*}{ Sumber Sampah } & \multicolumn{4}{c|}{ Rata-Rata Berat Sampah $(\mathrm{Kg}) /$ hari } \\
\cline { 3 - 7 } & & Organik & Kertas & Kayu & Plastik & Limbah B3 \\
\hline 1 & Fakultas Ekonomi & 0.37 & 2.42 & 0 & 4.51 & 0.12 \\
\hline 2 & FKIP & 0.66 & 3.67 & 0.97 & 6.06 & 0 \\
\hline 3 & Fakultas Pertanian & 0.4 & 1.72 & 0.61 & 4.82 & 0.15 \\
\hline 4 & Fakultas Teknik & 0.38 & 3 & 0 & 7.32 & 0.1 \\
\hline 5 & Kantin & 1.56 & 0.74 & 0 & 1.44 & 0 \\
\hline \multicolumn{2}{|l}{ Total } & 3.37 & 11.55 & 1.58 & 24.15 & 0.37 \\
\hline
\end{tabular}

Sumber: Survey, 2019

Dari tabel 3 dapat disimpulkan bahwa komposisi sampah jenis plastik paling banyak di hasilkan oleh UNU Kalbar yaitu sebanyak $24,15 \mathrm{~kg} /$ hari dan paling banyak bersumber dari Fakultas Teknik yaitu sebanyak 7,32 kg/hari. Secara keseluruhan persentase komposisi timbulan sampah di UNU Kalbar dapat dilihat pada Gambar 2.

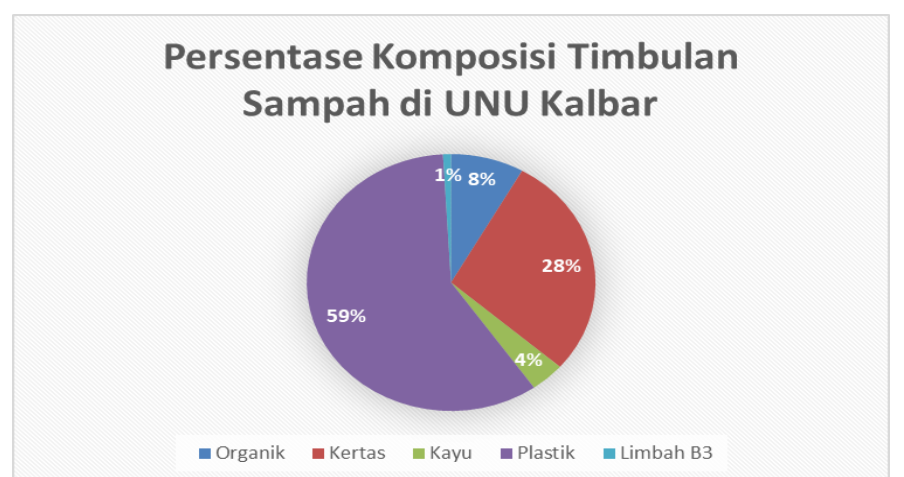

Gambar 2. Persentase Komposisi Timbulan Sampah di UNU Kalbar

Sumber: Survey, 2019

Pada gambar diatas dapat disimpulkan bahwa persentase komposisi timbulan sampah yang paling banyak yaitu sampah plastik dengan nilai 59\%, selanjutnya yang paling banyak yaitu sampah kertas dengan nilai $28 \%$ dan persentase sampah yang paling sedikit ada limbah B3 yaitu 1\%. Limbah B3 yang ditemui pada saat pengukuran komposisi tersebut yaitu sampah baterai dan pecahan neon serta kaleng cat.

\section{Karakteristik Sampah}

Selain komposisi, maka karakteristik lain yang biasa ditampilkan dalam penanganan sampah adalah karakteritik fisika dan kimia. Karakteristik tersebut sangat bervariasi, tergantung pada komponen-komponen sampah. Kekhasan sampah dari berbagai tempat/daerah serta jenisnya yang berbeda-beda memungkinkan sifat-sifat yang berbeda pula. Karakteristik Sampah di UNU Kalbar dapat dilihat secara terperinci pada Tabel 4. 
Tabel 4. Karakteristik Sampah di UNU Kalbar

\begin{tabular}{|l|c|c|l|}
\hline \multicolumn{1}{|c|}{ Karakteristik } & Satuan & Hasil & \multicolumn{1}{|c|}{$\begin{array}{c}\text { Metode yang } \\
\text { Digunakan }\end{array}$} \\
\hline Total Moisture & $\%$ & 56,57 & Gravimetric \\
\hline Nitrogen (N) Content & $\%$ & 0,14 & $\begin{array}{l}\text { AOAC (2016) } \\
955.04\end{array}$ \\
\hline $\mathrm{P}_{2} \mathrm{O}_{5}$ Content & $\%$ & 0,09 & $\begin{array}{l}\text { AOAC (2016) } \\
958.01\end{array}$ \\
\hline $\mathrm{K}_{2} \mathrm{O}$ Content & $\%$ & 0,74 & $\begin{array}{l}\text { AOAC (2016) } \\
955.06\end{array}$ \\
\hline Moisture Content & $\%$ & 0,25 & $\begin{array}{l}\text { AOAC }(2016) \\
950.01\end{array}$ \\
\hline Magnesium as Mg & $\%$ & 0,02 & AAS \\
\hline pH at $24.15^{\circ} \mathrm{C}$ & $\%$ & 5,80 & Potensiometric \\
\hline
\end{tabular}

Sumber: Uji Laboratorium, 2019

Berdasarkan hasil uji laboratorium bahwa kadar air sampah dari sampel yang diuji yaitu 56,57\%. Hal ini tidak sesuai dengan literatur dimana untuk sampah domestik tipikal kelembaban (kadar air) adalah 15 - 40\% (Tchobanoglous, 1993). Tujuan dari mengetahui kadar air sampah yaitu untuk merencanakan pengolahan sampah dengan menggunakan incinerator yang akan berpengaruh terhadap nilai kalor dan karateristik pembakaran.

Kadar abu merupakan sisa proses pembakaran pada suhu tinggi. Berdasarkan hasil uji laboratorium bahwa kadar abu sampah $0,25 \%$. Nilai tersebut sangatlah rendah dibandingkan dengan literatur yang didapat yaitu sebesar 10\%-30\% (Tchobanoglous, 1993) sehingga dengan kata lain proses pembakaran dengan suhu tinggi dapat menjadi alternatif pertimbangan dalam mengolah sampah di UNU Kalbar.

\section{Pewadahan Sampah}

Pewadahan merupakan penanganan awal dari pengelolaan sampah di UNU Kalbar yang selanjutnya akan ditampung di tempat penampungan sementara (TPS) sampah. Perlu diperhatikan bahwa tahap pewadahan sampah ini ditentukan berdasarkan hasil analisis jumlah timbulan sampah di UNU Kalbar pada setiap fakultas dan kantin di UNU Kalbar. Berdasarkan hasil analisis tersebut, diusulkan jenis tong sampah berdasarkan kapasitas daya tampung tong tersebut. Oleh karena itu penelitian ini mengusulkan tong sampah dengan kapasitas daya tampung 50 Liter yang ditempatkan di setiap fakultas dan kantin. Adapun rincian jumlah kebutuhan tong sampah 50 liter dapat dilihat pada tabel 5.

Tabel 5. Kebutuhan Pewadahan Sampah 50 Liter

\begin{tabular}{|c|l|r|c|}
\hline No & Sumber Sampah & $\begin{array}{c}\text { Rata-rata } \\
\text { Volume } \\
\text { Sampah/Hari } \\
\text { (liter) }\end{array}$ & $\begin{array}{c}\text { Kebutuhan } \\
\text { pewadahan 50 } \\
\text { liter (buah) }\end{array}$ \\
\hline 1 & Fakultas Ekonomi & 93.1 & 2 \\
\hline 2 & FKIP & 144.88 & 3 \\
\hline 3 & Fakultas Pertanian & 87.63 & 2 \\
\hline 4 & Fakultas Teknik & 123.05 & 2 \\
\hline 5 & Kantin & 27.76 & 1 \\
\hline
\end{tabular}


Berdasarkan tabel 5 bahwa volume sampah paling banyak bersumber dari FKIP UNU Kalbar yaitu mencapai 144,88 liter/hari sehingga kebutuhan tong sampah kapasitas 50 liter sebanyak 3 buah dan volume sampah paling sedikit bersumber dari Kantin UNU Kalbar yaitu mencapai 27,76 liter/hari sehingga kebutuhan tong sampah kapasitas 50 liter sebanyak 1 buah. Timbulan sampah di UNU Kalbar relatif sedikit dikarenakan UNU Kalbar tergolong universitas baru dengan jumlah akademika \pm 349 mahasiswa dan tenaga pendidik.

\section{Perencanaan Pola Pengumpulan dan Pengangkutan Sampah}

Secara umum, pola pengumpulan dan pengangkutan di UNU Kalbar masih dalam kategori sederhana. Hal tersebut dikarenakan jumlah timbulan sampah yang dihasilkan oleh seluruh civitas UNU Kalbar tidak banyak. Namun, dalam pengelolaan sampah di UNU Kalbar dapat direncanakan dengan langkah antara lain:

1. Pengelolaan sampah $3 R$

2. Pengumpulan sampah ke TPS UNU Kalbar

3. Pengangkutan sampah dari TPS UNU Kalbar menuju TPA Rasau Jaya.

Pola pengumpulan dan pengangkutan sampah yang direncanakan untuk diterapkan di UNU Kalbar dapat dilihat pada gambar 3.

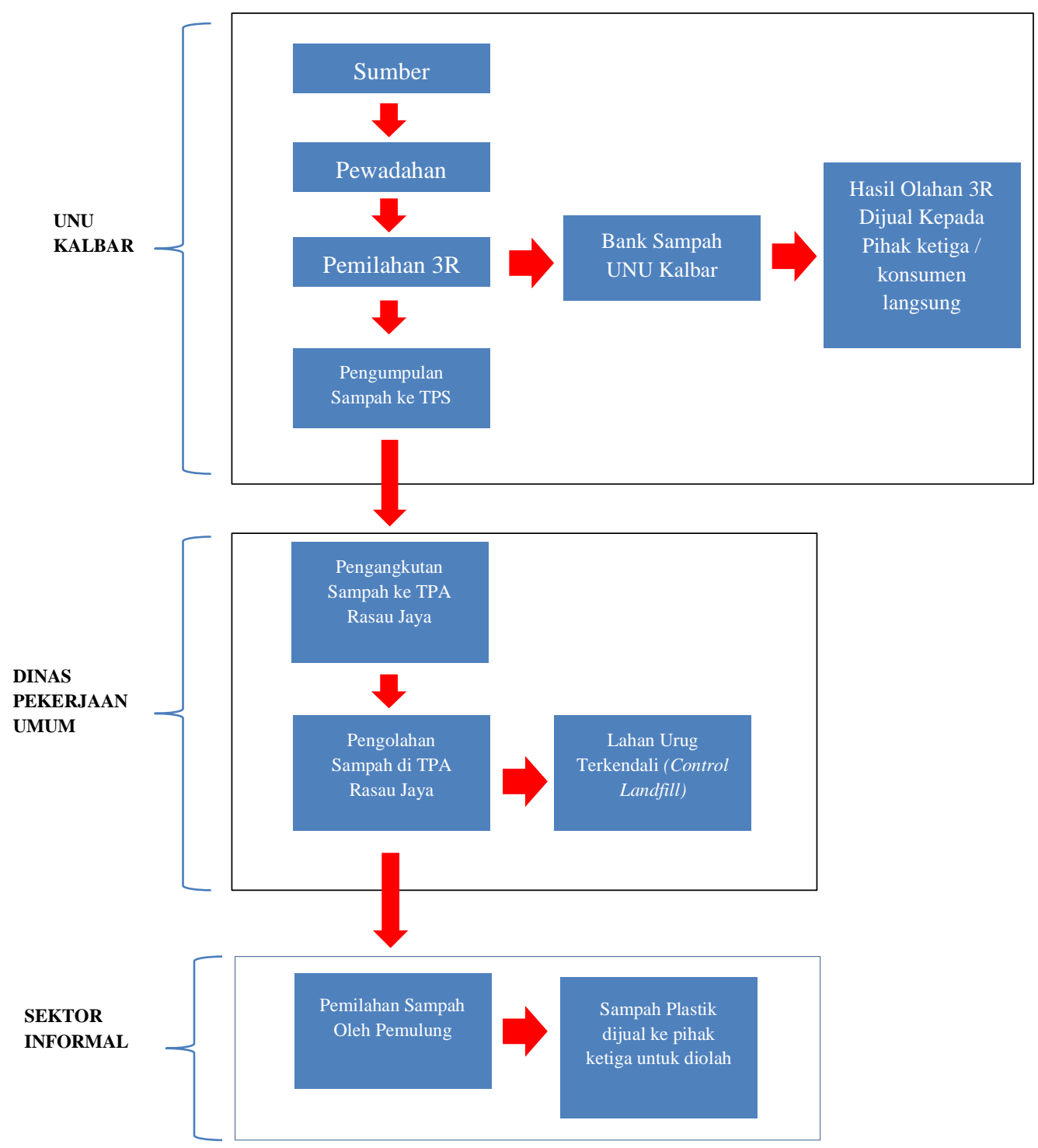

Gambar 3. Pola Pengumpulan dan Pengangkutan Sampah di UNU Kalbar (Sumber : Perencanaan, 2019) 


\section{Kelembagaan Pengelolaan Sampah}

\section{Universitas Nahdlatul Ulama Kalbar (UNU Kalbar)}

Penanganan sampah di UNU Kalbar harus memiliki struktur kelembagaan yang jelas. Struktur kelembagaan tersebut yang bertanggungjawab pada pengelolaan persampahan di UNU Kalbar. Fungsi dari struktur kelembagaan yaitu menyelenggarkan pelayanan persampahan dari sumber sampah sampai dengan TPS UNU Kalbar, membuat aturan dalam pengelolaan persampahan di UNU Kalbar dan pengendalian pelaksanaan pengelolaan persampahan di UNU Kalbar.

\section{Civitas Akademika}

Dalam pengelolaan sampah, peran civitas akademika dalam pengelolaan persampahan menjadi penting karena beberapa faktor. Pertama, civitas akademika sebagai penghasil sampah yang cukup besar karena sebagai akibat dari pola konsumsi civitas akademika di UNU Kalbar. Kedua, civitas akademika seharusnya bisa mandiri dalam memilah sampah sesuai dengan fasilitas tempat sampah yang telah disediakan oleh pihak UNU Kalbar. Hal tersebut dilakukan guna mendukung tercipta pengelolaan persampahan di UNU Kalbar.

\section{Dinas Pekerjaan Umum}

Penanganan sampah di Kabupaten Kubu Raya berdasarkan organisasi dan tata kerja perangkat daerah Kabupaten Kubu Raya merupaka tanggungjawab Dinas Pekerjaan Umum Bidang Cipta Karya. Pada gambar 3 dapat dilihat pada pola pengumpulan dan pengangkutan yang direncanakan peran dari Dinas Pekerjaan Umum yaitu sebagai pemberi pelayanan pengangkutan sampah dari TPS UNU Kalbar ke TPA Rasau Jaya serta melakukan pengolahan sampah di TPA dengan menggunakan metode lahan urug terkendali (controll landfill).

\section{Sektor Informal}

Salah satu sektor yang dapat memunculkan sektor informal di dalamnya adalah sektor pengelolaan sampah. Sektor informal dalam pengelolaan sampah merupakan salah satu bagian dari strategi masyarakat untuk bertahan hidup misalnya dalam hal ini masyarakat sebagai pemulung sampah di berbagai TPS dan TPA. Jumlah volume sampah yang semakin bertambah seiring dengan perkembangan penduduk tidak diimbangi dengan pelayanan pengelolaan sampah dan peningkatan lahan pemrosesan akhir. Sektor informal dalam pengelolaan sampah adalah pemulung. Pemulung yang berada di TPA Rasau Jaya merupakan bagian dari sistem kelembagaan pengelolaan persampahan. Walaupun saat ini pemerintah sebagai sektor formal belum mengoptimalkan peran sektor informal untuk berkontribusi secara maksimal, terfasilitasi maupun terlegitimasi dalam mereduksi timbulan sampah perkotaan melalui aktivitas pemanfaatan sampah bernilai ekonomis. Padahal sector informal merupakan pihak yang cukup potensial sebagai contributor reduksi sampah. Sektor formal yang ditunjuk oleh pemerintah masih belum optimal melakukan pemrosesan akhir sampah sehingga sektor informal berperan penting dengan didasari kebutuhan ekonomi sektor informal tersebut.

\section{Analisis dan Penentuan Lokasi TPS}

Penentuan lokasi Tempat Penampungan Sementara (TPS) sampah merupakan satu diantara hal yang penting dalam proses pengelolaan sampah. Lokasi penampungan harus dilakukan optimal dengan mengakomodir berbagai aspek yang relevan termasuk keberadaan TPS maupun sebaran sumber sampah. Berdasarkan hasil analisis lokasi sumber sampah dan rute terbaik dalam pengumpulan sampah pada perencanaan pembangunan gedung UNU Kalbar. Letak dan skenario rute pengumpulan sampah dari sumber menuju TPS UNU Kalbar dapat dilihat pada Gambar 4. 


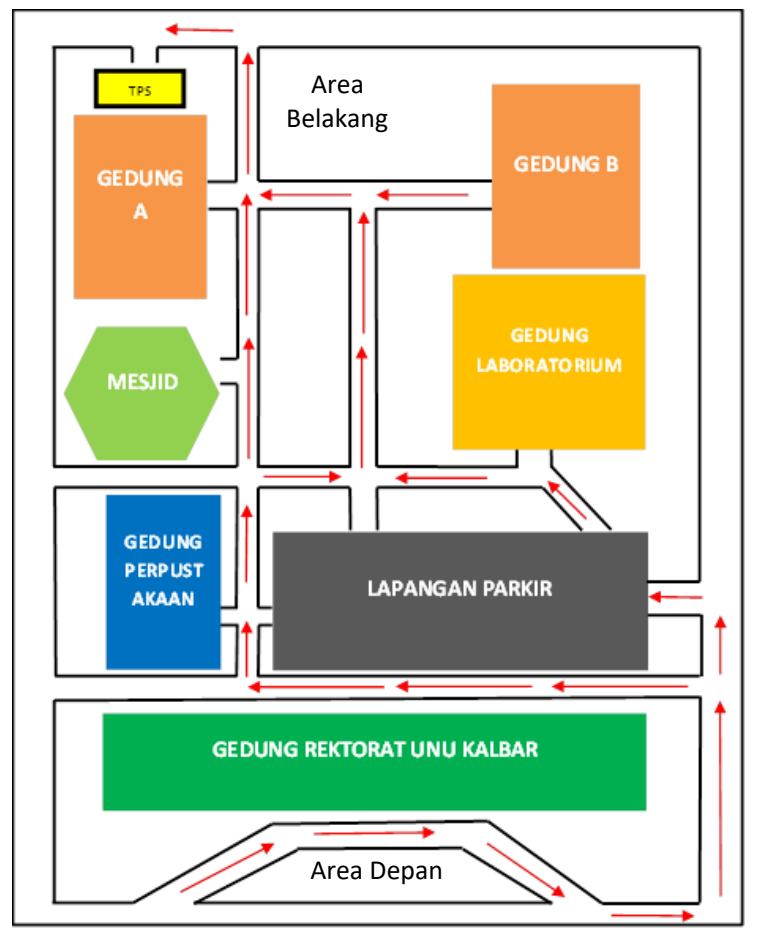

Gambar 4. Lokasi TPS UNU Kalbar dan Skenario Rute Pengumpulan Sampah (Sumber : Perencanaan, 2019)

Berdasarkan Gambar 4. terdapat 7 bangunan gedung yang merupakan sumber sampah di UNU Kalbar, oleh karena itu Tempat Penampungan Sampah UNU Kalbar akan diletakan pada bagian belakang wilayah perencanaan pembangunan UNU Kalbar. Pertimbangan lainnya terhadap penentuan lokasi TPS tersebut yaitu terkait dengan estetika dan dampak negatif dari TPS yaitu bau yang tidak sedap. Selain itu, rute pengumpulan sampah dapat diskenariokan dari bangunan pertama (depan) sumber sampah sampai dengan bangunan terakhir (belakang). Guna pelayanan pengumpulan sampah di UNU Kalbar diperlukan gerobak motor pengumpul sampah. Kebutuhan gerobak motor pengumpul sampah dapat dilihat pada Tabel 6 .

Tabel 6. Kebutuhan Gerobak Motor Sampah di UNU Kalbar

\begin{tabular}{|c|c|c|c|}
\hline Sumber Sampah & $\begin{array}{c}\text { Rata-rata Volume } \\
\text { Sampah/hari (liter) }\end{array}$ & $\begin{array}{c}\text { Rata-rata Volume } \\
\text { Sampah/hari } \\
\text { (meter }^{\mathbf{3}} \text { ) }\end{array}$ & $\begin{array}{c}\text { Kebutuhan } \\
\text { Gerobak Motor } \\
\text { Sampah 2.5 } \\
\mathbf{m}^{\mathbf{3}} \text { (unit) }\end{array}$ \\
\hline UNU Kalbar & 476 & 0.476 & 1 \\
\hline
\end{tabular}

Berdasarkan tabel diatas dapat dilihat bahwa rata-rata volume sampah setiap harinya di UNU Kalbar yaitu $0,476 \mathrm{~m}^{3}$. Berdasarkan data timbulan sampah tersebut, kebutuhan gerobak motor sampah dengan kapasitas 2,5 $\mathrm{m}^{3}$ yaitu sebanyak 1 unit.

\section{PENUTUP}

Kesimpulan yang bisa diambil dari penelitian ini adalah sebagai berikut :

1. Berdasarkan hasil pengukuran volume timbulan sampah di setiap fakultas dan kantin di UNU Kalbar bahwa rata-rata volume timbulan sampah di UNU Kalbar sebanyak 476,42 liter/hari dari 4 fakultas dan 1 kantin.

2. Berdasarkan hasil pengukuran volume timbulan sampah di setiap fakultas dan kantin di UNU Kalbar bahwa rata-rata volume timbulan sampah di UNU Kalbar sebanyak 476,42 liter/hari dari 4 fakultas dan 1 kantin. 
3. Jenis sampah yang paling banyak ditemukan yaitu sampah plastik sebanyak $24,15 \mathrm{~kg} / \mathrm{hari}$.

4. Penentuan lokasi TPS UNU Kalbar mempertimbangkan lokasi sumber sampah dan estetika sehingga lokasi tersebut dapat optimal pada saat operasional pengelolaan sampah.

5. Guna meningkatkan pelayanan pengumpulan sampah diperlukan gerobak motor sampah yang mengumpulkan sampah dari sumber-sumber sampah yang ada di UNU Kalbar.

Saran yang bisa kami berikan untuk kedepannya agar UNU KALBAR dapat melengkapi fasilitas persampahan sesuai dengan kebutuhan yang telah dikaji dan mengembangkan pengelolaan sampah sehingga menjadi green campus.

\section{DAFTAR PUSTAKA}

Christina, Etika.R.M. Cyntia. Samudro, Ganjar. Handayani, Dwi Siwi. 2016. Kajian Penentuan Metode Pengolahan Sampah Berdasarkan Timbulan, Komposisi, Dan Karakteristik Sampah Di Universitas Diponegoro (Studi Kasus: FSM, FIB, Dan D3 Teknik). ISBN 978-602-99334-5-1

Damanhuri, E. (2010). Diktat Pengelolaan Sampah Teknik Lingkungan. Institut Teknologi Bandung (ITB), Bandung.

Fadhilah A., dkk. 2011. Kajian Pengelolaan Sampah Kampus Jurusan Arsitektur Fakultas Teknik Universitas Diponegoro. MODUL Volume.11 nomor 2.

Febria, Sri. Darmayanti, Lita. Asmura, Jecky. 2014. Studi Timbulan Dan Komposisi Sampah Sebagai Dasar Perencanaan Sistem Pengelolaan Sampah di Kampus Bina Widya Universitas Riau. JOM FTEKNIK Volume 1 No. 2 Oktober 2014

Mirwan Mohammad.2008. Optimasi pengelolaan sampah di kampus UPN “Veteran” Jawa Timur. Jurnal Rekayasa Perencanaan 2008; 4 (2)

Purnaini, Rizki. 2011. Perencanaan dan Pengelolaan Sampah di Kawasan Selatan Universitas Tanjungpura. Jurnal Teknik Sipil Untan Volume 11 nomor 1.

Sartika. Faisya, Achmad Fickry. Ainy, Asmaripa. 2014. Analisis Implementasi Pengelolaan Sampah Di Kampus Unsri Inderalaya Tahun 2013. Jurnal Ilmu Kesehatan Masyarakat. Volume 5. 02 Juli 2014.

Simangunsong, Tuani Lidiawati. 2017. Pengelolaan Sampah Kampus untuk Mewujudkan Kampus Berkelanjutan (Sustainability Campus) . Prozima, Vol 1, No.1, Juni 2017, 59-63. E. ISSN. 2541-5115

SNI-T-12-1991-03 tentang Tata Cara Pengelolaan Sampah Pemukiman

SNI 19-3964-1994 tentang Metode Pengambilan dan Pengukuran Contoh Timbulan dan Komposisi Sampah Perkotaan

Tchobanoglous, G. (1993). Intergrated Solid Waste Management. McGraw Hill, New York. 